\title{
Pasado y presente en la resistencia de los pueblos originarios de Norteamerica
}

\author{
Past and present in the resistance of the originary peoples of North America
}

\author{
Juan Alberto Bozza \\ albertobozza2008@hotmail.com \\ Instituto de Investigaciones en Humanidades y \\ Ciencias Sociales, Facultad de Humanidades y Ciencias \\ de la Educación, Universidad Nacional de La Plata, \\ Argentina
}

Recepción: 11 Octubre 2019

Aprobación: 11 Agosto 2020

Publicación: 01 Diciembre 2020

Cita sugerida: Bozza, J. A. (2020). Pasado y presente en la resistencia de los pueblos originarios de Norteamerica. Aletheia, 11(21), e072. https://doi.org/10.24215/18533701e072

\begin{abstract}
Resumen: Este artículo analiza la vinculación entre la acción colectiva de las naciones originarias de Norteamérica y la revisión crítica del pasado americano. Describe el enfoque estigmatizador proyectado por la historiografía decimonónica hasta bien avanzado el siglo XX. Considera al movimiento por los derechos civiles de los años sesenta como la etapa matricial de la conciencia histórica india. Destaca el rol de las organizaciones militantes nativas que, fundadas en una visión alternativa y crítica del pasado, llevaron a cabo un conjunto de iniciativas encaminadas a la emancipación y autogobierno de los pueblos ancestrales. Estas acciones fueron decisivas para la construcción de una memoria de la resistencia de los pueblos nativos de Norteamérica.
\end{abstract}

Palabras clave: Naciones Originarias, Estados Unidos, Historiografía, Acción colectiva.

\begin{abstract}
This article analyzes the link between the collective actions of the original nations of North America and the critical review of the American past. It describes the stigmatizing approach projected by nineteenth-century historiography until well into the twentieth century. It considers the civil rights movement of the 1960s as the matrix stage of Indian historical consciousness. It highlights the role of the native militant organizations that, based on an alternative and critical vision of the past, carried out a set of initiatives aimed at the emancipation and self-government of ancestral peoples. These actions were decisive for the construction of a memory of the resistance of the native peoples of North America.
\end{abstract}

Keywords: Native Nations, United States, Historiography, Collective Action.

\section{LA HISTORIOGRAFÍA DE LA CONQUisTA DEL OESTE: ÉPICA Y ESTIGMATIZACIÓN}

El sometimiento de las comunidades aborígenes de Norteamérica concluyó en la década de 1890. Para la época, la expansión de la frontera había consumado el expolio, la deportación, el exterminio de algunas tribus y el encierro en reservaciones, territorios sometidos al gobierno federal privados de los beneficios del crecimiento económico de la nación. El hundimiento de las condiciones materiales y espirituales de existencia no fue el único padecimiento. La crónica y la literatura de masas edificaron una representación del pasado que 
estigmatizó las actitudes de los indios frente a los hombres blancos. También la producción de Hollywood acunó un relato épico de la conquista del Oeste que presentaba a los indios como comunidades gobernadas por la violencia y el odio irracional hacia los hombres civilizados (Pritzker, 2000).

La historiografía norteamericana del siglo XIX consagró a la ocupación territorial y al sometimiento de los aborígenes como zonas sagradas de la identidad de los Estados Unidos (Adams, 2008). Hasta fines de los años sesenta, las instituciones educativas norteamericanas transmitieron una imagen romantizada de la conquista del Oeste, en la que gobernantes y colonos blancos fueron los agentes del crecimiento y de la identidad de la nación. Por contraste, en dichos relatos los pueblos ancestrales encarnaban a los obstáculos de la naturaleza indómita y salvaje que los pioneros debieron someter.

Theodore Roosevelt, historiador, cazador de osos y, desde 1901, presidente de los Estados Unidos, edificó un potente relato triunfalista y racista del pasado americano. En el Harvard College obtuvo la reputación de historiador erudito cuyos libros llegaron a muchos lectores. Sus escritos sobre la Marcha hacia el Oeste le granjearon popularidad para su carrera política. En The Winning of the West suministró los perdurables tópicos racistas de la historiografía de la conquista. Roosevelt describía las "crueldades y depredaciones de los salvajes", la "traición" y la "duplicidad" de los indios, sus "innumerables hechos de rapiña y asesinato" (Turner, 1896). La supremacía técnica y racial de los colonos imponía la conquista del territorio indio. Esta interpretación del pasado fue el fundamento de las políticas contra los indios que pergeñó en su carrera hacia el poder. El presidente/historiador puso en práctica el sistema de asignación individual de tierras a los indios, destruyendo la propiedad comunitaria y utilizando parte de las tierras indias para la construcción de los Parques y Monumentos Nacionales (Landry, 2016).

Frederick Jackson Turner fue, tal vez, el historiador más aclamado por el público estadounidense de su época. Su narrativa sobre el avance de la frontera degradó la presencia de las naciones originarias. Como la mayoría de los intelectuales de su tiempo, Turner era un entusiasta de las teorías evolutivas eurocéntricas. La historia de la América "indómita” era, según el autor, un laboratorio experimental de las etapas universales de la evolución social; una carrera de postas cuyos portaestandartes eran, en orden de sucesión, cazadores y comerciantes de pieles, ganaderos, agricultores, mineros, manufactureros y la población urbana. La frontera era el agente de consolidación de la historia de Estados Unidos. En la lucha contra las fuerzas hostiles de la naturaleza -las tribus residentes en Norteamérica- los colonos modelaron un estilo de vida cuyas virtudes proyectaron a las leyes e instituciones de la joven nación.

Mediante una operación conceptual módica, pero efectiva, la historiografía épica de la frontera asociaba a los pueblos originarios con lo inanimado, tal como se infería de la utilización del concepto de "desierto" o "tierra libre", tierra que estaba allí para ser tomada en aras de la "civilización" (Turner, 1891). Turner carecía de una mirada precisa sobre la heterogeneidad de las comunidades nativas. Todos eran "salvajes" indiferenciados. Se aferró a este juicio cuando eran conocidos los escritos de Lewis Morgan sobre la diversidad de las organizaciones comunitarias indígenas y los grados de desarrollo que habían adquirido sobre las fuerzas de la naturaleza: cazadores, agricultores, consejos, confederaciones, liderazgos fuertes, liderazgos débiles, sin liderazgos, etc. (Morgan, 1877). Turner demostraba escaso interés en un análisis exhaustivo de estas complejidades. Examinaba el pasado en clave fatalista y teleológica. La derrota sufrida por las naciones nativas era el precio pagado para la construcción de un orden social civilizado (Nichols, 1972).

\section{DesPerTARES DE LA CONCIENCIA HISTÓRICA}

El relato estigmatizador de los aborígenes o su sustituto, el de su inevitable extinción, tuvo una vigencia poco disputada hasta la década de 1960. En ese período, las comunidades indígenas se plegaron al movimiento de lucha por los derechos civiles. Diversos grupos diseminados en el territorio, coordinaron y 
unificaron sus objetivos y actividades para incidir con mayor eficacia política en la obtención de fines específicos, rechazar normas y hábitos discriminatorios y repudiar medidas o legislaciones apañadas por las autoridades gubernamentales.

El emergente más destacado del proceso fue el American Indian Movement (AIM) (Dunbar-Ortiz, 2014). Se constituyó en Minneapolis, en el verano de 1968. Denunció los padecimientos contemporáneos de los indios, el alto desempleo, las viviendas precarias y el tratamiento racista. El Movimiento fue hostigado por el FBI, que pretendió eliminarlo mediante un programa de contrainsurgencia, el COINTELPRO(Churchill \& Vander Wall, 1990). El AIM desarrolló organizaciones comunitarias para atender la situación de los aborígenes en las grandes ciudades y promovió diversas formas de la acción colectiva. En 1969 apoyó la toma de la Isla de Alcatraz para la construcción de un centro cultural y comunitario en la prisión abandonada. Dos años después sus activistas escalaron el Monte Rushmore, denunciando el incumplimiento del Tratado de Fort Laramie. Este acuerdo, firmado en 1868 por el gobierno federal y las naciones Sioux y Arapaho, reconocía la propiedad india de los Black Hills y de los territorios de Wyoming, Dakota y Montana, prohibiendo la intrusión de los hombres blancos. El AIM organizó en 1972 el Camino de los Tratados Rotos, una caravana hacia Washington con representantes de todas las Naciones Nativas. La movilización elaboró un petitorio de reclamos al gobierno, entre los cuales, se pedía la conformación de una comisión mixta para pactar nuevos tratados con el gobierno; la revisión de las violaciones gubernamentales de los pactos del siglo XIX, la inmunidad de impuestos a los territorios indios, compensaciones económicas por los daños sufridos por las pérdidas de tierras, la restauración de 110 millones de acres (más de $445.000 \mathrm{~km}$ cuadrados) de tierra arrebatada a las Naciones Nativas, la petición de que los delitos contra los indios sean juzgados por la justicia federal, la construcción de mejores viviendas, inversión federal en educación, empleo y desarrollo comunitario; la abolición de la Oficina de Asuntos Indígenas (OAI) y la creación, en su reemplazo, de una nueva oficina de Relaciones Federales Indias (AIM, 1972).

La manifestación más trascendente del grupo fue la ocupación de la Oficina de Asuntos Indios en la aldea de Wounded Knee, Dakota del Sur, el 27 de febrero de 1973. El hecho puso en evidencia la humillación padecida por los habitantes de la reservación sioux y cuestionó las políticas instrumentadas por el presidente Richard Nixon y la gestión corrupta de la Oficina que administraba las tierras de la reservación.

La práctica política del $A I M$ animó a los activistas a repensar y refutar el pasado transmitido por las instituciones oficiales. La lucha contra las condiciones de marginación del presente interpelaba críticamente a las circunstancias del pasado en que tales condiciones fueron impuestas y a las narrativas que las reprodujeron y naturalizaron. La pugna por los derechos en el presente activó una práctica memorialista de recuperación y reexaminación del pasado.

\section{VOCES INDIAS E HISTORIA DESDE ABAJO}

La historiografía inclusiva del legado indio irrumpió por fuera del campo académico, cuando, a fines de los sesenta, Doris “Dee” Brown publicó Entierren mi corazón en Wounded Knee. Hasta entonces no existían en las universidades programas de investigación sobre historia india (Edmunds, 1989). Brown no era descendiente de indios, pero en Arkansas convivió con sus comunidades. Los testimonios de su memoria oral desmentían al retrato sombrío y caricaturesco construido por las crónicas de la frontera. El libro, definido como Una historia india del oeste americano, fue una temprana contribución al campo de la historia desde abajo. Brown criticaba el carácter incompleto y distorsivo de la historia nacional, circunscripta al protagonismo de las elites gobernantes (Sharpe, 1996; Brown, 1970). El texto fue construido en base a viejas fuentes, escasamente utilizadas, a testimonios emanados de las naciones indias y a documentos oficiales sometidos a una aguda mirada inquisitiva. Ofreció la primera visión integral e inclusiva del pasado norteamericano incorporando las experiencias padecidas por las tribus. Brown reconstruía minuciosamente el período entre 1860 y 1890, rememoraba los desplazamientos y relocalizaciones forzadas de los indios, los ataques devastadores del ejército norteamericano, los tratados firmados y violados por el gobierno federal; 
la destrucción de la cultura y de las religiones originarias. Alejado de los estereotipos vigentes, el autor restituía el estilo de vida generalmente apacible de los nativos y su voluntad de convivencia con los europeos. Según Brown, el tratamiento de la conquista del Oeste debía ser desacralizado y narrado en clave realista: el crecimiento económico capitalista se había fundado en un programa sistemático de desposesión de las tribus que había provocado padecimientos irreparables. El libro tenía otra característica novedosa. Ponía ante el lector la interacción de las conductas y proyectos de los grupos antagónicos; era una reconstrucción "de abajo hacia arriba", explicando las razones de las políticas de expulsión fomentadas por los gobiernos, pero también la resistencia de los indios de las grandes praderas, cuya agencia, afirmaba Brown, había frenado las alternativas más brutales de exterminio. Frente a la historia "de tambor y trompeta" (Green, 1902), Entierren mi corazón... profundizaba y completaba el conocimiento del pasado restituyendo un proceso de expolio, castigo y discriminación ignorado por la literatura convencional. La indagación elaboraba una descripción desprejuiciada de los líderes indios, casi siempre lapidados como jefes sanguinarios por las crónicas de la frontera. La evidencia recopilada demostraba que líderes como Pontiac, Sitting Bull, Sequoiah, Red Cloud, Crazy Horse, etc., tenían comportamientos racionales, no corroídos por el racismo, y concepciones complejas de las relaciones entre la naturaleza y los hombres.

Del seno del movimiento indio organizado surgieron sus propios historiadores. Vine Deloria pertenecía a la comunidad sioux de Dakota del Sur; ejerció como profesor de ciencias políticas e historia de las religiones indias en la Universidad de Arizona, donde sistematizó el primer máster sobre estudios indios. En 1969 publicó el libro/manifiesto Custer murió por tus pecados. El nombre del teniente coronel del VII ${ }^{\circ}$ Regimiento de Caballería simbolizaba, según Deloria, las políticas colonialistas más despiadadas. El libro deconstruía la visión del indio propalada por las corrientes dominantes de la cultura norteamericana. Procesando una vastísima documentación, analizó los 400 tratados y acuerdos firmados por los indios y el gobierno de los Estados Unidos, en los que se prometía el respeto de sus territorios y el mantenimiento de la frontera, y puso en evidencia el sistemático incumplimiento y la felonía por parte de los poderes estatales. En Deloria cohabitaron el investigador y el activista. Munido de su experticia histórica, abogó por la autodeterminación de las naciones indias y respaldó la lucha jurídica para la recuperación de derechos y territorios (Deloria, 1972 y 1988).

El activismo mantuvo viva la conciencia histórica india. El afianzamiento de las identidades culturales contribuyó a problematizar y, en varios casos, a refutar interpretaciones sobre el pasado de los pueblos nativos arraigadas en varias generaciones de estadounidenses.

\section{ACCIÓN COLECTIVA, RECTIFICACIÓN DEL PASADO Y MEMORIAS DE SUPERVIVENCIA}

\section{Combates contra el olvido. La masacre del Rio Marías}

La acción colectiva india iluminó procesos opacados por la historiografía tradicional que, por lo general, eran episodios de violencia estatal desaforada. El olvido diluyó la masacre de la Nación Piegan en el Río Marías, ocurrida en Montana el 23 de enero de 1870. Allí, el ejército de los Estados Unidos, al mando del mayor Eugene Baker, mató a 173 pobladores, en su mayoría mujeres y niños.

El hecho ocurrió durante una escalada de hostilidad entre la Confederación Blackfoot, de la que eran parte los Piegan, y los colonos. El disparador del conflicto era una práctica recurrente, la violación del territorio indio por la apropiación inconsulta de los colonos de sus recursos naturales (Bennet, 1982). Como respuesta, grupos de guerreros comenzaban a practicar robos y ataques en los establecimientos radicados en el suelo comunitario. Luego de una de estas refriegas, el general William T. Sherman envió un regimiento a la zona. Aunque no encontraron a la tribu que había refugiado al autor de los ataques, el mayor Baker ordenó arrasar a otra aldea, cuyo jefe, Heavy Runner, estaba en buenas relaciones con los blancos. Se trató de un plan vengativo 
que diezmó a casi toda una comunidad. Algunos sobrevivientes, infectados de viruela, fueron obligados por el ejército a marchar sin caballos, ni ropa y comida a la lejana localidad de Fort Benton. La mayoría murió de frío (Hutton, 1985). La masacre no fue el único golpe sufrido por Piegan. El otro, la desaparición de los búfalos de las praderas de la región, completó una devastación que ciertos estudiosos emparentaron a un genocidio (Schontzler, 2012). Los sostenedores de esta noción aludían a que la impunidad y el fomento institucional del olvido eran políticas que acompañaban a las prácticas genocidas.

Como veremos, la reconstrucción de los hechos torna difícil refutar aquella noción. Las autoridades gubernamentales encubrieron los sucesos. El general Sherman desvió la investigación y silenció a los testigos militares que habían decidido testificar. El comunicado castrense definió a la indefensa aldea como un campamento de "guerreros". Baker, el responsable de los crímenes, nunca fue acusado (History.com Editors, 2019).

El ocultamiento del evento duró más de un siglo. Los textos históricos no mencionaron el incidente y fue difícil localizar el lugar del suplicio. A fines del siglo XX, Carol Murray, residente en la reservación, se enteró del acontecimiento cuando ingresó en la universidad. Como presidenta del Colegio de la Comunidad Blackfoot e historiadora tribal, entrevistó en 1970 a una anciana que, por temor a ser encarcelada, aún se negaba a dar testimonio.

Un hecho cultural resquebrajó el muro del silencio. En 1986, la novela Fool Crows de James Welch, inspirada en los padecimientos de su abuela sobreviviente, permitió que algunos estudiantes de Montana se enteraran de los crímenes (Schontzler, 2012). El libro de Welch movilizó a una comunidad decidida a dar batalla contra el olvido. "No fue una batalla; fue un crimen de guerra del gobierno de los Estados Unidos", proclamó Bob Burns, representante de la nación Blackfoot, en Shelby (Ratledge, 2010).

El sistema educativo comunitario impulsó la declaración del lugar del martirio como un sitio de memoria. Además de afirmar una voluntad de supervivencia, la decisión rectificaba la elusión de los relatos históricos. Desde 1987, cada 23 de enero, la profesora Murray puso en marcha un seminario de estudio sobre el acontecimiento que incluía el viaje de los estudiantes al Rio Marías. El proyecto memorialista también identificó a los descendientes de las víctimas. En 2010, logró la presencia de los parientes lejanos de Heavy Runner, el jefe Piegan asesinado por los soldados de Baker, y de estudiantes de secundaria de otras ciudades de Montana.

La conmemoración, realizada en el lugar de los asesinatos, reforzaba los sentimientos de continuidad y resistencia del pueblo. En ella participaron las instituciones ancestrales y reverdecieron los símbolos de los antepasados: los miembros de la Crazy Dogs Society, el grupo guerrero que brindaba protección a la tribu, las banderas de la Nación Blackfoot y las salvas de 21 disparos en homenaje a los muertos. Además de recordar a las víctimas y desnudar la impunidad establecida por los gobernantes, la ceremonia recuperó las dimensiones individuales de la catástrofe, el impacto sobre las subjetividades de los represaliados. Las historiadoras a cargo del proyecto narraron las peripecias de la niña Long Time Calf. Con apenas ocho años, había cargado a su pequeña sobrina y nadado en las gélidas aguas del río. Herida en una pierna, caminó dos días por las colinas hasta un campamento donde halló cobijo. La voluntad de vida de la niña, corriendo por el territorio donde luego se emplazó la aldea, era un legado de perseverancia y cohesión para una nación sobreviviente.

La comunidad bregó por la construcción de un memorial en homenaje a las víctimas. El Baker Massacre Memorial se erigió en 2010 en el sitio de la fosa donde fueron arrojados los muertos. "Ahora estamos visitando nuestra patria, dijo la historiadora tribal, y estamos reconociendo la resistencia de nuestra gente" (Ratledge, 2010).

Otros actos de memoria debieron refutar interpretaciones falaces no menos penosas del pasado indio. 


\section{Sand Creek, rectificación de una historia engañosa.}

Además de ser el nombre de un río, Sand Creek fue un episodio luctuoso del pasado del pueblo Cheyenne. En la región sureste de Colorado, el 29 de noviembre de 1864 el coronel John Chivington y la Guardia de Voluntarios de Colorado, masacraron un campamento conjunto de Cheyennes y Arapahos.

La represalia ocurrió en una coyuntura de intensificación de las presiones de los colonos sobre el territorio indio. El primer tratado de Fort Laramie (1851) había reconocido a los nativos la propiedad de sus tierras, "mientras los ríos fluyeran y el sol brillara" según el protocolo indio (Nemattanew, 2002). Eran amplias llanuras que limitaban hacia el oeste con las Montañas Rocosas. El descubrimiento de oro en Colorado, en 1858, provocó una vasta intrusión de aventureros que hizo trizas a las promesas gubernamentales. Los Cheyennes fueron obligados a firmar un nuevo "acuerdo" en 1861 en Fort Wise. El mismo amputó severamente la extensión de los campos de caza. Los jóvenes guerreros, renuentes a vivir en una región donde escaseaban los bisontes, rechazaron el tratado. Como consecuencia, una sucesión de tiroteos y robos de ganado, enturbiaron la convivencia entre indios y blancos. Sin que hubiera declaración de guerra, en 1864 el ejército comenzó a destruir un gran número de campamentos y a asesinar, sin motivo alguno, a jefes indios que estaban cazando (Hoig, 1980). La retaliación por parte de los Cheyennes encendió la hoguera.

En la madrugada del 29 de noviembre, un batallón de 650 soldados al mando de Chivington atacó a la aldea del jefe Black Kettle matando a 200 indios, en su mayoría no combatientes, y mutilando a los escasos sobrevivientes. Las órdenes impartidas por el general Phillip Sheridan revelaban el propósito de exterminar a la Nación Cheyenne. El mensaje instigaba a una guerra total, sin límites. Todos los componentes del asentamiento debían experimentar "los horrores de la guerra tan plenamente como los guerreros". Los testimonios de Chivington mostraban la misma furia vengativa (Brown, 1970).

Aunque el hecho no fue olvidado, la historiografía de la conquista lo disolvió en un relato artificioso, lleno de rodeos y subterfugios. Guenter Lewy fue su expositor más destacado. Sinteticemos las proposiciones con las que mitigaba un crimen de Estado.

En la primera interpretación, Lewy afirmaba que el ejército norteamericano no estaba involucrado en la matanza. Los responsables eran los miembros del Cuerpo de Voluntarios de Colorado, una tropa estatal formada por colonos indisciplinados y mineros resentidos. Sin embargo, el comandante que ordenó la represalia era el coronel John Chivington, un pastor metodista y político cuyo proselitismo reclamaba la necesidad de exterminar a los indios, incluyendo a los niños (Brown, 1970). El eslabón principal de la cadena de responsabilidades remitía al ejército de los Estados Unidos.

La proposición anterior -el ejército no estaba involucrado en la masacre-, era desmentida por Lewy, para quien matanzas como la de Sand Creek debían ser consideradas como accidentes no deseados de "la guerra contra los indios" (es decir, la guerra entre el ejército de los Estados Unidos y las tribus). Como veremos más adelante, esta afirmación se alojaba en una tesis más amplia que explicaba los conatos de violencia aberrante como eventos fatales de una "trágica colisión de culturas".

El término "la guerra contra los indios" fue un eufemismo utilizado abusivamente por algunos historiadores para enmascarar decisiones que debían explicarse como castigos expiatorios o actos de venganza (Stannard, 1993; Lewy, 2004). Con gran ingenio, Lewy evitaba tratar las intrusiones de los colonos, los empresarios y el ejército como actos inconsultos, llevados a cabo de hecho, sin declaración de guerra alguna. Además, el autor parecía ignorar que el estado de guerra impedía la comisión de atrocidades, como la muerte y el martirio de los prisioneros, disparar sobre los no combatientes, quemar aldeas, arrancar el cuero cabelludo (scalp) de la víctima, etc. Al insertar los actos de extermino masivo como eslabones indiferenciados de una guerra, y peor aún como batallas, la explicación histórica opacaba la responsabilidad de los perpetradores específicos de los crímenes, que eran funcionarios de agencias estatales.

Otra interpretación especiosa tendía a atenuar la matanza. Según Lewy, los Cheyennes y Arapahos eran portadores de una cultura de la violencia: atacaban a los blancos por el placer de infringir daño y dolor. 
Esos fieros instintos sumían la vida de los colonos en una atmósfera de perpetuo temor. Al referir los acontecimientos de $S$ and $C r e e k$, Lewy no podía negar que las tribus luchaban por reclamos legítimos contra los invasores de sus tierras. A pesar de este reconocimiento, ubicaba como causa de la masacre a la actitud belicosa de la cultura guerrera. Los indios, al decir del autor, luchaban "por la pura alegría del combate", por el deseo de botín y porque conseguían prestigio en las batallas contra los blancos. Esta conducta provocaba la reacción violenta de los colonos, que urgían a los militares a realizar acciones vengativas drásticas, o bien las ejecutaban por mano propia. En opinión de Lewy, la instigación de los colonos había inducido a las tropas a atacar al campamento con la orden de no dejar sobrevivientes. El argumento del autor era más inquietante. Los militares no tenían otra alternativa que perpetrar el sacrificio masivo del campamento (Lewy, 2012).

Otra explicación igualaba las violencias. Al describir el clima de tensiones acumuladas en Colorado, Lewy equiparaba los actos de furia, oscureciendo la trama específica de las disputas realmente en juego. No distinguía entre la violencia ejercida por usurpadores del territorio indio y la que provenía de quienes se resistían al despojo. El resultado era un relato donde el pasado era una secuencia abigarrada de actos destructivos indistintos, todos motivados por la venganza.

Citaremos el último argumento de Lewy. Más que explicar los hechos, parecía escrito para exonerar la responsabilidad de las fuerzas estatales. Según el autor, en las ciudades del este norteamericano había existido un atisbo de conciencia de culpa; se alzaron voces críticas y una comisión del congreso pidió información sobre la "Batalla de Sand Creek". En otros términos, la responsabilidad oficial se atenuaba porque algunos funcionarios insinuaron la incorrección de los actos. La narración de Lewy no resistía la prueba de los hechos. Las manifestaciones de las autoridades fueron promesas inocuas. Nunca se presentaron cargos contra los perpetradores de la masacre.

A fines del siglo XX las comunidades Cheyennes y Arapahos del Norte de Colorado peticionaron al Servicio de Parques Nacionales erigir en la región un sitio de memoria. El Sand Creek Massacre National Historic Site se inauguró en el nuevo milenio. El gesto de restitución fue incompleto e insincero. Las referencias oficiales del Parque seguían reiterando una explicación no muy distinta de la de Lewy. Las semillas de la Masacre de Sand Creek debían buscarse en la presencia de dos culturas históricamente discordantes dentro de un área geográfica que codiciaron por razones dispares. Es decir, fue una tragedia (Sand Creek Massacre, 2017).

La banalización de los crímenes de Estado, como efectos indeseados de una guerra, impregnó a la memoria oficial del Estado de Colorado. El gobierno elevó un monumento en Denver, en los terrenos del Capitolio. Sand Creek fue definida como una de las batallas donde lucharon las tropas de Colorado en la Guerra Civil.Recién en 2002 hubo una pálida, casi insubstancial, rectificación. La Asamblea General del Estado autorizó a un grupo de historiadores a colocar una placa adicional donde se informaba que "se había caracterizado mal a Sand Creek como una batalla" (Calhoun, 2013).

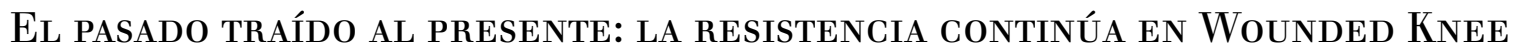

Las acciones colectivas analizadas se convocaron en lugares sensibles de la memoria india; en comarcas donde padecieron formas brutales de violencia institucional distorsionadas por la historiografía conservadora. La develación y el recuerdo de tales episodios legitimaron política y moralmente resistencias y demandas vigentes en el presente.

El 27 de febrero de 1973, los activistas del American Indian Movement ocuparon la Oficina de Asuntos Indios en Wounded Knee, Dakota del Sur. La elección del sitio no fue casual. Casi un siglo antes, la aldea sufrió un feroz ataque del Séptimo Regimiento de Caballería. El evento estaba olvidado y, en el campo académico, había sido objeto de interpretaciones amañadas. La espectacular ocupación, reflejada al instante por los grandes medios de comunicación, desnudó las deplorables condiciones de existencia en las reservaciones, en este caso, del pueblo Sioux. El AIM denunció a las políticas federales del presidente Richard Nixon ejecutadas a través de la Oficina de Asuntos Indios, un ente carcomido por la indolencia y la malversación de fondos. 
La ocupación en el sitio de la masacre del 29 de diciembre de 1890 recibió la solidaridad de grupos de la nueva izquierda, que abastecieron con alimentos a los resistentes. Simultáneamente, la toma de la aldea durante 71 días motivó un dispositivo represivo de gran magnitud, en el que intervinieron el FBI, del Cuerpo de Alguaciles de los Estados Unidos y el ejército. La comunidad fue sitiada, se le cortaron los servicios, se impidió el ingreso de alimentos y en las refriegas fueron muertos dos militantes y encarcelados los dirigentes indios (Churchill, 1996). Hechos más graves, pero sin tanta visibilidad mediática, acaecieron en los años posteriores. El FBI realizó razzias en la reservación dando muerte a varios nativos (Mattiessen, 1992). Mas ataques recrudecieron al descubrirse carbón y uranio en las entrañas de los Black Hills, las colinas sagradas de los Sioux. En sucesivas escaramuzas fueron asesinados varios nativos y dos agentes federales. Los tribunales de justicia condenaron, sin pruebas consistentes, a los líderes del AIM, Robert Robideau, Dino Butler y Leonard Peltier (Mattiessen, 1992).

La ocupación de Wounded Knee también cuestionó a los relatos de la historiografía dedicada a los temas militares y de expansión de la frontera. En efecto, durante gran parte del siglo XX, este tipo de investigaciones suavizaron o desfiguraron las características del suceso. La masacre fue calificada como la "batalla de Wounded Knee” ¿Era en verdad una batalla? Las evidencias que glosaremos a continuación refutan tal calificación.

Aprisionada en un magro territorio, la Nación Sioux intentó sobreponerse al estado de humillación rehabilitando un viejo ritual, la Danza Fantasma (Ghost Dance). El baile reforzaba la identidad en tiempos de incertidumbre y de líderes asesinados (Utley, 2004); despertaba la esperanza del fin de la opresión, prometía el retorno del búfalo y la recuperación de la autonomía tribal. Los jefes militares la prohibieron por considerarla el presagio de una rebelión y el Departamento de Guerra desplegó 7.000 soldados en derredor de Wounded Knee(King, 2016).

El campamento fue atacado por sorpresa por medio millar de soldados. La metralla arrasó a más de 200 nativos, en su mayoría mujeres, ancianos y niños. Algunos fueron ultimados cuando yacían heridos en sus tipis (tiendas) y otros rematados cuando huían por los barrancos cercanos. Hasta la naturaleza pareció asociarse a la impunidad. Una copiosa nevada congeló y sepultó los cuerpos que, días después, fueron enterrados en una tumba colectiva.

La historiografía militar trató el hecho como un accidente de guerra donde no podían ser condenados los protagonistas enfrentados; era el producto inevitable de un "choque de culturas". La interpretación deshistorizaba al evento. Se lo desconectaba del proceso de desposesión y encierro de los Sioux para presentarlo como una tragedia producida por dos violencias irracionales. Este juicio fue consagrado por Robert Utley (Utley \& Washburn, 2002).

Utley fue una figura prominente de la historiografía del Oeste, además de haber cursado una gran carrera como oficial del Servicio Nacional de Parques. Según esta perspectiva, la operación militar debía ser juzgada como el fruto desgraciado de una colisión de culturas. Los militares y los indios eran presentados como prisioneros de pulsiones que los hacían actuar sólo de una manera, la de aniquilar al rival. Utley fetichizaba una acción destructiva puntual como si fuese el único desenlace posible de una pugna entre culturas y valores irreductibles. Pero la apelación a una determinación general, epodía explicar situaciones concretas prescindiendo del análisis de las órdenes impartidas, de las responsabilidades institucionales y del abanico de opciones al alcance de los actores involucrados? El "choque de culturas" ¿obligaba a asesinar a niños, rematar a fugitivos o, como acostumbraba el teniente coronel Custer, aniquilar a la dotación de caballos de los indios? Si esto era así, ¿̨por qué "el choque de culturas” no desembocó, en otras refriegas coetáneas, en el exterminio masivo de las aldeas? La "guerra" del general Crook contra los apaches de Cochise y Mangas Coloradas (1862-1872) fue sangrienta, pero el destino trágico mentado por Utley no produjo la aniquilación global de asentamientos indios. El concepto de "choque de culturas" ofrecía un recurso narrativo cómodo, tranquilizador, pero inconsistente.

La historiografía contrahegemónica, la indigenista y la que, sin serlo, compartió sus cuestionamientos, exhibió un conjunto de fuentes que demostraban una gama de actitudes disímiles de los protagonistas y 
testigos de los sucesos de Wounded Knee. Las mismas no encajaban en el recitado del inevitable "choque de culturas". Tales fuentes mostraban que algunos actores involucrados en el suceso manifestaron tribulaciones, disensos y malestar ante la comisión de hechos brutales. Por caso, en el Senado de los Estados Unidos se alzaron voces que deploraron los actos criminosos masivos del ejército. Altos oficiales, como Nelson Miles y George Crook, también expresaron repugnancia por hechos de esa calaña. Eran pruebas al alcance de historiadores medianamente perspicaces. Utley subestimaba o silenciaba tales fuentes. Su metodología reproducía un viejo recurso criticado por la renovación historiográfica surgida en la posguerra. Edward H. Carr lo llamó "fetichización" de los documentos, un embeleco heredado de la historiografía positivista decimonónica (Carr, 1984). En efecto, Utley reconstruyó los hechos replicando, como único fundamento de la narración, los juicios contra los indios de las autoridades militares, de la Oficina de Asuntos Indios y de la prensa de la época, todos compactamente hostiles contra la Nación Sioux. Dichos documentos presentaban arbitrariamente a los chamanes como agitadores fanáticos. Utley utilizaba conceptualizaciones extemporáneas aplicadas a los nativos. Definía como "progresistas" a los indios que aceptaban las políticas del gobierno y nominaba conservadores a los que resistían la desposesión de sus tierras. Analizaba con una irritante trivialidad el deterioro de las condiciones de supervivencia de los indios. Glosaba la desaparición de los búfalos como una fatalidad de la naturaleza, sin reparar en las responsabilidades de militares y de comerciantes de pieles en la destrucción súbita de las manadas (Utley, 2004).

Investigaciones más recientes, como las de Peter Cozzens, seguían reproduciendo la tesis de las masacres “trágicas y accidentales". Según este autor, las fuentes primarias no revelaban que los oficiales del ejército tuvieran concepciones inherentemente antagónicas respecto de los indios (Cozzens, 2016). Esta conclusión volvía a desnudar la cojera de su perspectiva metodológica. Su relato se fundaba en documentos emanados de las instituciones y los sujetos implicados en crímenes en gran escala y en declaraciones de testigos hostiles a los indios. La mayor parte de la prensa de la época congeniaba con los pronunciamientos gubernamentales. Sus crónicas vitoreaban al ejército que había sofocado, en Wounded Knee, una insurrección que los Sioux habían perpetrato con propósitos vengativos. Los reportes de la prensa inmediatos al evento señalaban la "traición" de los indios y destacaban la actuación heroica del Séptimo Regimiento de Caballería (Kelley, 1971). Utley y Cozzens se mostraron displicentes frente al carácter parcial, antagónico e interesado de los emisores de tales juicios. La empatía de las fuentes periodísticas con los objetivos militares ¿no era una disposición que podía favorecer el encubrimiento de la devastación de Wounded Knee? Pero el apañamiento y la desinformación sobre la matanza no fue una cuestión exclusiva de la prensa antinativa. El Estado Federal también contribuyó a extender un manto de impunidad sobre los sucesos. A pesar de los tribunales de honor y de las promesas de condenas, en 1891 el presidente Benjamín Harrison premió con Medallas de Honor a las tropas responsables de los asesinatos (Lone Hill, 2013).

La elusión y la distorsión gravitaron sobre el evento traumático. Como se dijo, los historiadores militares seleccionaron y jerarquizaron los documentos con criterios que, con cierta ingenuidad, podríamos calificar como desequilibrados. Como discípulos tardíos de Ranke, manifestaron una predilección unilateral por un tipo de fuentes, las oficiales. Pero, a pesar de esa inclinación, tampoco fueron consecuentes. Desconocieron o desdeñaron a los documentos cuya información no encajaba en sus perspectivas. Algunas preguntas son necesarias, ¿por qué no valoraban como una fuente relevante a las opiniones del general Miles? Porque suministraba respuestas indeseables e incómodas: Wounded Knee no había sido una tragedia, sino una masacre deliberada causada por las malas decisiones del coronel Forsyth, a cargo del Séptimo de Caballería (Ostler, 2004). De modo análogo, se desestimaron los testimonios de los nativos que fueron testigos directos de los sucesos ¿Acaso no eran fuentes primarias significativas los testimonios de sobrevivientes de Wounded Knee, como Black Elk, Turning Hawk y American Horse? Sí, lo eran. Pero daban vívidos detalles de una matanza consumada deliberadamente (Neihardt, 2008; "Lakota Accounts of the Massacre at Wounded Knee", 2001). 


\section{Palabras finales}

Aunque estigmatizado por los medios conservadores, el $A I M$ fue un protagonista destacado del movimiento emancipador de los pueblos nativos. La coordinación de las protestas con otras organizaciones obligó al gobierno a abandonar la política de Terminación de las Tribus y de destrucción de las etnias. El Estado tuvo que devolver millones de hectáreas de tierras y debió admitir la aprobación de leyes favorables a la identidad cultural, a la soberanía indígena y al autogobierno tribal (Warrior \& Chaat Smith, 1996).

El despertar de la acción colectiva afirmó la conciencia histórica de las Naciones Originarias. El movimiento puso en tela de juicio a los relatos de la historiografía del Oeste. Los estudios históricos pioneros comenzaron a germinar a finales de los años sesenta. La nueva historiografía del indigenismo restituyó otras voces, amplió el repertorio de las fuentes y abrió una senda productiva para el despliegue de una historia desde abajo. El interés por el conocimiento de los pueblos ancestrales logró ganarse un espacio en la investigación académica, en el desarrollo de programas e institutos en las universidades.

La acción colectiva construyó y afianzó la memoria india. Las ocupaciones de territorios e instituciones y las movilizaciones políticas recuperaron los sitios de la memoria, dieron la batalla contra el olvido y consolidaron la cohesión e identidad cultural de los pueblos originarios. Los investigadores vinculados a este movimiento permitieron que segmentos traumáticos del pasado fueran revelados y esclarecidos. Alentaron una mirada crítica sobre la historiografía; revisaron y rectificaron relatos tradicionales e interpretaciones artificiosas. Impulsaron a las investigaciones académicas a recorrer debates perturbadores, como la cuestión del genocidio en la colonización de Norteamérica. La historiografía indigenista contribuyó a una visión enriquecida y complejizada del pasado americano. Los frutos de su producción combinaron el rigor analítico y el compromiso crítico que le infundieron sus pioneros. Quizás este compromiso perdure mientras "el sol brille y los ríos sigan fluyendo".

\section{REFERENCIAS}

Adams, S. (2008). The Early American Republic: A Documentary Reader. Maiden (MA): Wiley-Blackwell.

AIM. (1972). Trail of Broken Treaties. 20-Points Positions Paper. Minneapolis, Minnesota, October. Recuperado de: http://www.aimovement.org/ggc/trailofbrokentreaties.html

Bennett, B. (1982). Death, Too, for the Heavy Runner. Missoula, MO: Mountain Press Publishing.

Brown, D. A. (1970). Bury my Heart at Wounded Knee. New York: Henry Holt and Company.

Carr, E. H. (1984). ¿Qué es la historia?. Buenos Aires: Ariel.

Calhoun, P. (2013), Sand Creek Massacre and John Chivington's explosive actions 11 years after Glorieta Pass. Westword, March 27. Recuperado de: https://www.westword.com/news/carlin-dunne-killed-at-pikes-peak-int ernational-hill-climb-11398427

Churchill, W. \& Vander Wall, J. (1990). The Cointelpro's Papers: Documents from the FBI's Secret Wars Against Dissent in the United States. Boston: South End Press.

Cox Richardson, H. (2015). The Medal of Honor and the Wounded Knee Massacre. We're History, New York, March 25. Recuperado de: http://werehistory.org/medal-of-honor-wounded-knee/

Cozzens, P. (2016). The Earth Is Weeping: The Epic Story of the Indian Wars for the American West. New York: Alfred Knopf.

Deloria, V. (1972). Of Utmost Good Faith. New York: Bantam.

Deloria, V. (1988). Custer Died for your Sins. Norman: University of Oklahoma Press.

Dunbar-Ortiz, R. (2014). An Indigenous Peoples' History of the United States. Boston: Beacon Press.

Fitch Kelley, W. (1971). Pine Ridge, 1890; an eye witness account of the events surrounding the figting at Wounded Knee. San Francisco, CA: P, Bovis. 
Green, J.R. (1902). Short History of the English People. London: Macmillan.

History.com Editors (2019). Soldiers massacre the wrong camp of Indians, History, July 28. https://www.history.co $\mathrm{m} /$ this-day-in-history/soldiers-massacre-the-wrong-camp-of-indians

Hoig, S. (1980). The Peace Chiefs of the Cheyennes. Norman, OK: University of Oklahoma Press.

Hutton, P. A. (1985). Forming Military Indian Policy: 'The Only Good Indian Is a Dead Indian'. En P. A. Hutton, P. A., Phil Sheridan and His Army. Lincoln, NE: University of Nebraska Press.

King, P. J. (2016). The Truth about the Wounded Knee Massacre. Indian Country Today, December 30. Recuperado de: https://newsmaven.io/indiancountrytoday/archive/the-truth-about-the-wounded-knee-massacre-PIQqU KeCEEmnLeQn0Q5SOQ/

Landry, A. (2016). Theodore Roosvelt, The Only Good Indians Are the Dead Indians. Indian Country Today, June 28. Recuperado de: https://newsmaven.io/indiancountrytoday/archive/theodore-roosevelt-the-only-good-ind ians-are-the-dead-indians-oN1cdfuEW02KzOVVyrp7ig/

Lewy, G. (2004). Were American Indians the Victims of Genocide?. Commentary, September. Recuperado de: https: //www.commentarymagazine.com/articles/were-american-indians-the-victims-of-genocide/

Lewy, G. (2012). Essays on Genocide and Humanitarian Intervention. Salt Lake City: The University of Utah Press.

Lone Hill, D. (2013). The Wounded Knee medals of honor should be rescinded. The Guardian (Internationaledition), February 18. Recuperado de: https://www.theguardian.com/commentisfree/2013/feb/18/massacre-wounded -knee-medals-honor-rescinded

Mattiessen, P. (1992). In the Spirit of Crazy Horse: the Story of Leonard Peltier and the FBI's War on the American Indian Movement. New York: Penguin Books.

Morgan, L. (1971). La sociedad primitiva. Barcelona: Ayuso.

Neihardt, J. (2008). Black Elk Speaks: Being the Life Story of a Holy Man of the Oglala Sioux. New York: SUNY Press.

Nemattanew (Chief Roy Crazy Horse). (2002). The North American Genocide. Rancocas, NJ: Powathan Press.

Nichols, D. (1972). Civilization Over Savage: Frederick Jackson Turner and the Indian. South Dakota History. Wisconsin: South Dakota State Historical Society.

Ostler, J. (2004). The Plains Sioux and U.S. Colonialism from Lewis and Clark to Wounded Knee. New York: Cambridge University Press.

Pritzker, B. (2000). A Native American Encyclopedia: History, Culture, and Peoples. New York: Oxford University Press.

Ratledge, M. (2010). BCC marks 26th commemoration of Baker Massacre. Glacier Report, Montana, March 10. Recuperado de: http://www.cutbankpioneerpress.com/glacier_reporter/news/article_bccbcfb1-748e-5209-88 56-89d332ef5f50.html

Roosevelt, T. (1896). The Winning of the West. New York and London: G.P. Putnam's Sons.

Sand Creek Massacre (2017). National Historic Site. Colorado. August 17. Recuperado de: https://www.nps.gov/sa nd/learn/historyculture/index.htm

Schontzler, G. (2012). Blackfeet remember Montana's greatest Indian massacre. Bozeman Daily Chronicle, Montana, January 25. Recuperado de: https://www.bozemandailychronicle.com/news/sunday/blackfeet-remember-mon tana-s-greatest-indian-massacre/article_daca1094-4484-11e1-918e-001871e3ce6c.html

Sharpe, J. (1996). "Historia desde abajo". En P. Burke (ed.), Formas de hacer historia (pp. 38-58). Madrid: Alianza.

Stannard, D. (1993). American Holocaust: The Conquest of the New World: The Conquest of the New World. New York: Oxford University Press.

Sumner, W. G. (1911). Essays of William Graham Sumner, edited by Keller, A. and Davie, M., 2 vols. New Haven, Conn: Yale University Press.

Turner, F.J. (1891). “The Character and Influence of the Indian Trade in Wisconsin”. En H. B. Adams (ed.), John Hopkins Universities Series in Historical and Political Science, 9th ser. Vols. (11-12), November and December.

Turner, F. J. (1896). "Review of Winning of the West". American Historical Review, 2, October. 
Utley, R. M. \& Washburn, W. (2002). Indian Wars. New York: American Heritage Press.

Utley, R. M. (2004). The Last Days of the Sioux Nation. New Haven: Yale University Press.

Warrior, R. \& Chaat Smith, P. (1996). Like a Hurricane: The Indian Movement from Alcatraz to Wounded Knee. New York: New Press.

Weston P. J. (2016). Kill Every Buffalo You Can! Every Buffalo Dead Is an Indian Gone. The Atlantic, Washington D.C., May 13. Recuperado de: https://www.theatlantic.com/national/archive/2016/05/the-buffalo-killers/48 $2349 /$ 